\title{
The Financial And Cost Accounting Implications Of The Increased Role Of Advanced Nurse Practitioners In U.S. Healthcare
}

Paul J. Carruth, Southeastern Louisiana University, USA Ann K. Carruth, Southeastern Louisiana University, USA

\begin{abstract}
On March 23, 2010, the Affordable Care Act became law. The need for healthcare reform was prompted by an imperative to reduce the relentless increase in spending on medical care in the United States. One approach to examining and solving the problem of escalating costs is to focus on applying proven principles of evidence-based practice and cost-effectiveness practices to find the least-expensive way to ensure clinical services of acceptable quality without sacrificing patient satisfaction. Advanced practice registered nurses (APRNs) have positioned themselves to serve an integral role in national health care reform. A successful transformation of the nation's health system will require utilization of all clinicians, including highly qualified APRNs, to provide costeffective, accessible, patient-centered care. There is extensive, consistent evidence that nurse practitioners (NPs) provide care of equal or better quality at lower cost than comparable services provided by other qualified health professionals. However, current policies in many states prevent NPs from practicing within their full, legally defined scopes of practice. The Office of Technology Assessment's conclusions noted in 1981 that APRNs can be substituted for physicians in a significant portion of medical services with at least similar outcomes. Since then, numerous studies have supported that the care provided is equal to those provided by physicians for services within the overlapping scopes of licensed practice. This paper combines economic analysis with review of literature on health care reform initiatives to explore how the goals of healthcare reform can be accomplished by advanced nurse practitioners to provide their wide range of services directly to patients in a variety of clinical settings.
\end{abstract}

Keywords: Healthcare Reform; Mid-Level Providers; Healthcare Accounting

\section{INTRODUCTION}

ith tens of millions of uninsured or underinsured individuals in the U.S. combined with higher deductibles imposed from health insurance companies, the demand for cost-effective health care options is on the rise (McCallum and Jacoby, 2009). With the 2010 health care reform legislation, insurance coverage will be expanded for the entire population, advantaged and disadvantaged, causing the uninsured to drop significantly. One assertion made by this legislation is that U.S. citizens will receive improved quality of care as a result of expanded coverage. This will result in improvement in the effective management of disease and injury. On the negative side, health care costs will rise, especially among those who seek preventive and chronic care. This assertion is supported by Hadley and Holahan's statistical analysis indicating that extended coverage would increase health care spending by $3 \%$ to $6 \%$ (2003). As a result of the passage of this legislation, it is estimated that more than 32 million additional Americans will soon gain health insurance, and thus access to health care. This article analyzes the cost implications of using nurse practitioners (NPs) to address the rising need for new mid level providers under the new Affordable Care Act of 2010. 


\section{THE COST OF HEALTH CARE FOR ALL}

U.S. health care is costly, fragmented, and complex. Each year, new technologies, medical devices, medications and procedures are added to the continuum of research to practice. Healthcare comprises approximately 1.4 trillion dollars or 15\% of the Gross Domestic Product (Center for Medicare and Medicaid Services, 2005). Health care costs continue to rise at two-and-a half times the rate of inflation in the economy. Estimates indicate that by 2016 , health care costs will reach 20 percent of the GDP. It is generally thought that healthcare in the U.S. is better than many industrialized countries. In fact, even though the U.S. per-capita expenditures on health care are 20 percent higher than any other nation, key health indicators such as infant mortality (23rd) and life expectancy (28th) are well below many other nations. The poor and uninsured are the most likely group to use the ED inappropriately for minor health complaints, because of a lack of or inadequate health insurance (Koska, 1989). Knowing this, healthcare insurance agencies are responding by examining ways to provide cost effective care. One way to save money is to shift costs to employees through premium increases, higher deductibles, and more out-of-pocket payments.

Hospital care and prescription drugs are responsible for much of the overall escalation in health care spending (Pear, 2004), and accounted for 30\% and 11\% of the total increase between 2002 and 2004, respectively (Smith, Cowan, Heffler, \& Catlin, 2006). Expenditures on antibiotics make up approximately $15 \%$ to $30 \%$ of pharmaceutical costs, accounting for the largest proportion among drug categories (Ansari, 2001; Ansari, Gray et al., 2003).

Managed care has profoundly affected the delivery of health care in the United States in recent years. It was originally intended to provide cost-effective healthcare services (Council on Graduate Medical Education [COGME], 1997); Health Resources and Services Administration [HRSA], 1999). However, over time managed care has become associated with multiple financial arrangements with cost controls imposed by employer-paid health plans and insurance companies. This has influenced relationships, generated conflicts and ethical dilemmas, fostered negativity and created frustration. As a result many providers and consumers of health care distrust the system (Hayes, 2003; HRSA, 1999). Not unlike physicians, some difficulties arise because nurse practitioners do not understand the managed care system or the economic aspects of health care (Hayes, 2002, 2003). If NPs are unable to adapt to the demands of a constantly changing healthcare environment, or if they harbor negative attitudes about managed care, they may convey those attitudes to patients, thus fostering patient doubt about the adequacy of their NP-provided care.

\section{ECONOMIC IMPACT OF MID LEVEL PROVIDERS AND THE ROLE OF NURSE PRACTITIONERS IN THE HEALTHCARE MARKETPLACE}

The cost of health care doubled from 1990-2001 and is projected to double again by the year 2012 (www.prevent.org). Research supports that $50 \%$ of health-care expenditures are attributed to preventable lifestyle health behaviors. These lifestyle exposures contribute to many diseases including type 2 diabetes, hypertension, heart disease, stroke, and some forms of cancer and obesity. According to the Center for Disease Control and Prevention (CDC, 2002), each year at least 300,000 people die from illnesses associated with obesity; 440,000 die from illnesses attributed to cigarette smoking; and $40 \%$ of all deaths are caused by heart disease or stroke.

Nurse practitioners (NPs) are in a unique position to deliver high-quality care to meet the increase healthcare needs of the U.S. population. Although certain aspects of the nurse practitioner role may differ among various practices and populations, increasing competition for access to patients makes it incumbent on nurse practitioners to document the cost-effectiveness of their care (Vincent, 2002). NPs are health care providers who provide primary care, ambulatory care, acute care, specialty care, and long-term care. The NP role was created in 1965 as a response to shortages in trained physicians in the US. NPs rank as one of the fastest growing health-care professions. According to the American Academy of Nurse Practitioners, there are approximately 140,000 NPs qualified to practice. NPs are trained at the masters or doctoral level to provide care in a specialized area. NP students spend 600 hours or more training with MDs or NPs in their specialization. Boards of Nursing in each state regulate practice and grant state licensure once certification exams are passed. Most NPs work collaboratively with physicians. However, 11 states currently allow independent NP practice. While the American Medical Association 
opposes increasing autonomy of NPs, regulatory changes are inevitable given the enactment of the new Affordable Care Act of 2010.

The need for healthcare reform was prompted by an imperative to reduce the relentless increase in spending on medical care in the United States. Changes in health care delivery are expected since more Americans will be insured and will be able to seek care from approved providers. It is estimated that 32 million newly insured Americans will enter the system by 2014. In addition, the predicted 40,000 primary-care doctor shortfall by 2020 will further drive up the need for more NPs or other physician assistants.

\section{TRENDS IN NUMBER OF NPS}

For at least a decade, the United States has experienced worsening workforce shortages in the health professions. The American Association of Medical Colleges projects a nationwide shortage of 45,000 primary care physicians by 2020 , and shortages are predicted in all other health disciplines including nursing, oral health, and behavioral health.

The physician workforce is aging. Many physicians are nearing retirement just as the growth of an aging population and advances in technology contribute to a growing demand for physician services http://bhpr.hrsa.gov/healthworkforce), hence the growing demand for a strong NP workforce. According to the "National Sample Survey of Registered Nurses 2008: Initial Findings" there were an estimated 158,348 nurse practitioners with credentials as NPs in the United States. This represents an increase from an estimated 141,209 NPs in 2004 http://bhpr.hrsa.gov/healthworkforce/rnsurvey/.

\section{CONSIDERATIONS FOR RETURN ON INVESTMENT}

A cost analysis can provide critical efficiency information and an accurate understanding of cost structures necessary for appropriate treatment pricing, appropriate bidding for managed-care contracts and financial stability. Because more nurse practitioners work in offices and clinics, a comparison of production costs and efficiency can be evaluated (Vincent, 2002).

The concept of return on investments (ROI) should be used to examine cost effectiveness of care provided by nurse practitioners compared to other healthcare physician extenders, such as physician's assistants. Return on investment typically refers to short-term financial benefit, usually within 1-5 years of making a decision, secured in return for a short-term financial investment. Many physicians understand that once NPs are employed by their practice, they will require additional training. Benefits of investments are often characterized by cost reductions. The cost effectiveness analysis is the ratio of the net cost of an investment, in this case the cost of national healthcare, to a defined health outcome. A cost-effectiveness analysis of healthcare examines long - term cost savings and long term outcomes. When compared to other ratios, the lowest ratio is considered the most cost effective. In order for the government and other healthcare insurance carriers to feel that the return on investment is worthwhile, the current cost of healthcare must be offset by the improved health outcomes and long-term cost savings.

To evaluate the investment of using NPs in practice, a time frame for the analysis must be determined and financial data gathered. When conducting a cost analysis, the first step is to decide on the perspective, as costs included in the analyses will vary depending on the perspective selected. The most common types of costs used in cost analyses are direct and indirect costs, fixed and variable costs, and opportunity costs. Many of the costs associated with NPs involves salary. The average salary of NPs is considerably less than physicians, and significantly less than physicians who specialize. Data are examined using other cost categories. Direct costs are easily identified, are often controlled by the manager, and include all of the goods, services and other resources consumed in production. Examples of direct costs are laboratory equipment, supplies, personnel, diagnostic services and rent for office space (Finkler, Ward, Baker, 2007; Luce et al. 1996). Indirect costs, such as business overhead, can be more challenging to determine than direct costs. However, failure to take these costs into consideration can lead to erroneous cost-control strategies. Examples of indirect costs are housekeeping and other contracted services (Finkler, Ward, \& Baker, 2007). Other cost categories are fixed and variable. Fixed costs do not vary with a change in the number of client visits or services provided, while variable costs do (Finkler, Ward, \& Baker, 2007). Rent for 
the NPs space, certain support personnel salaries, and equipment are all fixed costs. Chart supplies and disposable supplies are examples of variable costs. As a practice increases the number of patients seen during a set period of time, more supplies are needed, thereby increasing the amount of money the practice spends to treat patients. In a cost analysis, cost data such as financial statements are examined and categorized. The categories should have the following elements: the categories must be relevant to the situation; the categories should be distinct and not overlap; and the categories must cover all possibilities (Finkler \& Hanson 1995).

Salaries and benefits and other compensation for staffing are often placed in one category, and all costs for supplies in another category. On the other hand, focusing on operations is another approach where costs can be classified based on the function or activity for which the resources are used. (West, West \& Malone, 1998). Arbitrary allocations are avoided, and costing accuracy is improved because inputs are linked to the resources of the corresponding activities, such as scheduling patient visits, meeting with pharmaceutical representatives, checking in new patients, and assessing and treating patients. Monetary value can be assigned once all cost data have been identified and categorized. In most instances, market prices yield a reasonable estimate of opportunity costs (Luce et al. 1996). Depreciation must be calculated when determining costs for capital goods. Labor costs are separated into hourly wages, and fringe benefits should be separated from wages. Replacement costs should also be included in the cost analysis (Finkler \& Hanson 1995). When all costs have been identified and valued, they are totaled and an efficiency analysis is performed.

Most cost analyses in health care use gross cost-estimation methods (Finkler \& Hanson 1995). In this method, all costs are totaled and indirect costs are arbitrarily allocated to services or products. A cost-per-patient or cost-per-visit ratio by the NP is determined by calculating the total costs of production and dividing this figure by the total number of patients or patient visits. Gross costing is often simpler and more straight-forward to calculate but the arbitrary allocation of indirect costs can result in cost distortion and faulty conclusions about profitability. In attempting to reduce or control costs, health-care executives could incorrectly reduce or eliminate activities or services that appear to be unprofitable (West \& West 1997). For gross costing, total costs are divided by the total number of the clients or client visits that are NP specific to obtain a cost-per-patient or cost-per-visit ratio. In the case of NPs, however, activity-based costing may be more useful because the care involves more than one functionality. This type of costing, however, requires a detailed inventory and measurement of resources used, and is time-consuming. To improve accuracy in estimating resource consumption by avoiding arbitrary, total indirect cost allocations must be determined. These costs would need to be categorized into cost pools representing various resources, and activities associated with those resources identified. These activities are known as cost or activity drivers (West \& West 1997). An example would be the time that NPs spend on different types of client visits. The time necessary for NPs to perform an annual pap and pelvic examination may be substantially different than the time needed for NPs to perform a wellness visit. In each case, the cost of production will be affected by the amount of time and the salary and benefit cost of the NP. Once all costs are identified and linked to an appropriate activity, a summary measure is obtained for each activity. Direct and indirect costs are summed to obtain the total cost, and a cost-per-client or client visit is calculated. Understanding and managing operational costs are crucial in attaining financial stability. With the anticipated increase in insured Americans entering the health care system, cost analysis of NPs will continue to be significant in establishing their role in providing affordable access to more Americans.

\section{THE IMPACT ON EXPANDED COVERAGE TO MORE U.S. CITIZENS}

If preventive and chronic care reduced costly urgent events, why do costs continue to rise? First, goodquality preventive and chronic care, though cost-effective, do not in general reduce costs. Second, improved chronic and urgent care extends the lives of persons who often have costly conditions (Kaiser Family Foundation, 2009). Costs have been found to be $42 \%$ lower for intermediate and skilled care residents and $26 \%$ lower for those with long-term stays (Hummel and Pirzada, 1994). Third, higher care utilization resulting from increased coverage and quality of care reduces the availability of sufficient numbers of physicians, especially for disadvantaged patients.

As a result of these issues, minor acute events that would otherwise have resulted in a visit to a Primary Care Physician (PCP) increasingly shifted to more costly care in hospital emergency departments. Overloaded physicians and the inability to obtain timely care, are at the root of strain on the health care system. Because physicians lack the capacity to improve preventive and chronic care for all of the additional patients who obtain 
coverage, it is speculated that the health of the disadvantaged population will not improve nearly as much as that of the advantaged population. Recent experience in Massachusetts confirms that limited PCP capacity undercuts the effect of expanded insurance coverage (Kowalczyk, 2009; Steinbrook, 2008).

Increasing health care visits will result in the need to increase PCP or mid-level providers' office efficiency. A more efficient office has lower operating expenses and allows providers to see more patients in a day without decreasing quality. Reduced expenses, in turn, raise providers' incomes and encourage more medical students, physician assistants and nurse practitioners to become providers. As a result of expanded coverage, a lack of PCP availability means newly insured will have difficulty finding a regular source of primary care.

\section{EFFECTIVENESS OF NURSE PRACTITIONERS IN PROVIDING HEALTHCARE}

Nurse practitioners (NPs) are a large part of the healthcare delivery workforce (Cooper, Laud, \& Dietrich, 1998) and have been shown to provide quality, cost-effective care associated with high degrees of patient satisfaction (Hayes, 2007; Pinkerton \& Bush, 2000). Extensive documentation indicates that for most healthcare situations, prevention and early access to care is more cost effective than treatment for chronic illnesses caused by lifestyle choices.

Researchers have compared the quality and effectiveness of care provided by NPs with that given by physicians. Recent studies compared outcomes of care provided by nurse practitioners with those of physicians and found no significant differences in health status, physiological measures, patient satisfaction, or health-service utilization (Brown \& Grimes, 1995; Mundinger et al., 2000; Paez \& Allen, 2006).

In addition, NPs are highly skilled in providing comprehensive assessments, which result in clinical decisions that are safe as well as cost effective (Mundinger et al., 2000). Other studies have reported both favorable outcomes associated with the utilization of NPs in acute care settings, especially as reflected on reduced length of stay and hospital costs (Cowan et al., 2006).

Others have reported similar NP cost-effective patterns associated with medical prescriptions. Researchers have found that the NP model for drug prescriptions is cost effective in various settings (Cowan, et al, 2006; Chen et al, 2009; Murphy et al, 2009). More research is need, however, on the patterns and prevalence of drug utilization among NPs in primary care practices.

Research supports that NP delivered care is cost-effective. Unique in healthcare, NPs respond to evolving trends that include wellness and consumer based health care demand. Many studies have documented the effectiveness of nurse practitioner care. Providers who deliver superior outcomes at comparable costs are at a competitive advantage in any health-care system. In a watershed study, the Office of Technology Assessment (1981; 1986) found that NPs provided equivalent or improved medical care compared to physicians. The mean 2009 salary for NPs across disciplines in the US was \$90,200 (American Academy of Nurse Practitioners [AANP], 2009). This is significantly less that than the median compensation for primary care physicians.

Numerous studies have demonstrated the cost savings of NP managed clinics (Chen, McNeese-Smith, Cowan, Upenieka, and Afifi, 2009; Chenowith, Martin, Pankowski, and Raymond, 2005; Chenowith, Martin, Panowski and Raymond, 2008; Hunter, Ventura, and Keams, 1999; Paez and Allen, 2006; Sears, Wickizer, Franklin, Cheadie, and Berkowitz, 2007). According to the American Medical Group Association (2009), the mean salary for family care MDs was $\$ 198,000$ and internal medicine was $\$ 205,000$, substantially more than NPs. Research has shown that when productivity measures, salaries, and costs of education are taken into consideration, NPs are cost effective providers of health care. This is especially relevant in rural areas where there is critical shortage of MDs.

A number of previous literature reviews of the role of advanced practice nurses (APNs) in primary care settings have suggested that nurses can provide care which is equivalent to that provided by doctors in these settings. Research in Europe supports the theory that patients were generally more satisfied with consultations from nurse practitioners than with doctors. These findings were supported by published randomized controlled trials (RCTs). 
In 2000, Venning et al. examined cost- effectiveness of general practitioners and nurse practitioners in primary care. No significant differences were found in prescribing or health outcome for the two groups. Patients were more satisfied with nurse consultations, even when length of consultation was controlled for. The authors concluded that outcomes of care and cost were similar between the two groups; if nurses could reduce consultation time and return rate they could become more cost effective

Although individual studies do contribute to evidence about the effectiveness of care between doctors and nurses, the most robust evidence is in the form of systematic reviews and meta- analysis, of which there are relatively few examples. Thus, it is difficult to make firm generalizable or internationally based conclusions from the literature. It is clear, however, that randomized studies, in specific areas of advanced nursing practice, do support the view that nurses can provide care at least equivalent to doctors, although the full cost/benefit implications of this are not clear with the evidence currently available. It should also be noted that in some cases the outcome measures utilized for these studies are short term and it is not clear what the long term benefits are. Kitzman \& Groth (2003) report research studies that include long term outcomes of advanced practice nursing. These studies indicate that long term outcomes of care from advanced practice nurses compared to traditional services, when the diagnosis is already established, are at least equally good to traditional services.

\section{ECONOMIC IMPLICATIONS}

The economic evaluation and implications of doctor/nurse skill- mix and advanced-practice roles have been reported (Kernick and Scott 2002), and frameworks within which this could be assessed have been published (Carroll and Fay 1997; Vincent 2002; Kernick and Scott 2002). The estimation of costs when the services of advanced practitioners are under-utilized has also been proposed (Nichols 1992). A number of recent of economic evaluations have been undertaken to examine the cost-effectiveness of specific nurse-led services. The results of these studies are mixed and the implementation of nurse-led services are reported variously as cost neutral, higher cost, or lower cost ((McGrath 1990).

\section{TRANSITIONING TO A NEW HEALTHCARE DELIVERY SYSTEM}

Linking outcome data with cost data is one method for illuminating the value of nurse practitioner practice. If clinical outcomes for nurse practitioners are similar or better than other health-care providers and costs are less, then nurse practitioners could become the preferred provider for these services and establish the value of nurse practitioner practice. Similarly, if costs and outcomes are comparable, customer satisfaction will be an advantage. By specifying cost-effective areas, nurse practitioners can identify market niches, seek out business possibilities, and develop strategies for obtaining desirable new business.

It is imperative that NPs document the cost effectiveness of care in order to receive recognition and support. The most cost-effective providers are likely to also be the most marketable, and the savviest at reimbursement through third-party payers, and thus the most successful.

\section{AUTHOR INFORMATION}

Paul J. Carruth, Ph.D., CPA is a Professor of Accounting at Southeastern Louisiana University. He can be reached at Southeastern Louisiana University, School of Business, SLU Box 10468, Hammond, LA. He has written extensively about healthcare issues. E-mail: pcarruth@selu.edu

Ann K. Carruth, DNS, RN is a Professor of Nursing and Interim Dean at Southeastern Louisiana University. She can be reached at Southeastern Louisiana University, School of Nursing \& Health Sciences, SLU Box 10781, Hammond, LA 70402. She too has written extensively about healthcare issues. E-mail: acarruth@ selu.edu 


\section{REFERENCES}

1. American Association of Colleges of Nursing (2000). Nurse Practitioners: The Growing Solution in Health Care Delivery. Retrieved February 20, 2011 from http://www.aacn.nche.edu/Media/FactSheets/npfact.htm.

2. American Medical Group Association (2009). 2009 Physician Compensation Survey. Retrieved February 20, 2011 from http/://www.cehkasearch.com/compensation/amga.

3. Ansari, F. (2001). Utilization review of systemic anti-infective agents in a teaching hospital in Tehran, Iran. European Journal of Clinical Pharmacology, 57(6-7), 541-546.

4. Ansari, F., Gray, K., Nathwani, D., Phillips, G., Ogston, S., Ramsay, C., et al. (2003). Outcomes of an intervention to improve hospital antibiotic prescribing: Interrupted time series with segmented regression analysis. Journal of Antimicrobial Chemotherapy, 52(5), 842-848.

5. Brown, S. \& Grimes, D. (1995) Nurse Practitioners and Certified Nurse-Midwives: a Meta-Analysis of Studies on Nurses in Primary Care Roles. Nursing Research, 44 (6), 332-339.

6. Carroll T and Fay V (1997) Measuring the impact of advanced practice nursing on achieving cost-quality outcomes: issues and challenges. (Advanced Practice Providers), Nursing Administration Quarterly, 21 (4) 32-39.

7. Centers for Disease Control and Prevention (CDC), National Center for Chronic Disease Prevention and Health Promotion. Chronic Disease Prevention: Overview. www.cdc.gov/nccdphp/overview.htm. In CDC. The Burden of Chronic Diseases and Their Risk Factors. National and State Perspectives. 2002.

8. Centers for Medicare and Medicaid Services. (2005). Table 1, National Healthcare Expenditures and Selected Economic Indicators, Levels, and Annual Percent Change: Selected Calendar Years 1990-2013 from www.cms.hhs.gov/statistics/he

9. Chen, C., McNeese, D., Cowan, M., Upenieks, V., \& Afifi, A. (2009). Evaluation of a nurse practitionerled care management model in reducing inpatient drug utilization and cost, Nursing Economics, May-June, 27 (3) 160-168.

10. Chenoweth, D., Martin, N., Pankowski, J., \& Raymond, L. (2005). A benefit-cost analysis of a worksite nurse practitioner program: First impressions. Journal of Occupational and Environmental Medicine, 47 (11), 1110-6.

11. Chenoweth, D., Martin, N., Pankowki, J., \& Raymond, L. (2008). Nurse practitioner services. Three-year impact on health care costs. Journal of Occupational and Environmental Medicine, 50 (11), 1293-1298.

12. Cooper, R., Laud, P., \& Dietrich, C. (1998). Current and projected workforce of non-physician clinicians. Journal of the American Medical Association, 280, 788-794.

13. Cowan, M., Shapiro, M., Hays, R., Afifi, A., Vazirani, S., Ward, C., et al. (2006). The effect of multidisciplinary hospitalist/physician and advanced practice nurse collaboration on hospital costs. Journal of Nursing Administration, 36(2), 79-85.

14. Council on Graduate Medical Education. (1997). Resource paper: Preparing learners for practice in a managed care environment. Washington, DC: U.S. Department of Health and Human Services.

15. Finkler, S.A., Ward, D. M., \& Baker, J. (2007). Essentials of cost accounting for health care organizations (3rd ed). Jones and Bartlett learning.

16. Finkler, S. A. \& Hanson, K. L. (1995). Innovations by primary care health centers: lessons for managers and policy makers. Journal of Ambulatory Care Management, 18 (2). 74-80.

17. Hadley J, \& Holahan J. (2003) Covering the uninsured: how much would it cost? Health Aff (Millwood). (suppl web exclusives). W3-250-W3-265.

18. Hayes, E. (2002). Challenge and opportunity: Nurse practitioner programs partnering with managed care. Journal of the American Academy of Nurse Practitioners, 15(11), 501-508.

19. Hayes, E. (2003). Nurse practitioner self-confidence and attitudes towards managed care. Journal of the American Academy of Nurse Practitioners, 14(11), 498-50.

20. Hayes, E. (2007). Embattled and embittered and empowered and evolving: Nurse practitioner attitudes toward managed care. Journal of American Academy of Nurse Practitioners, 19, 143-151. doi:10.1111/j.1745-7599.2006.00208.x.

21. Health Resources and Services Administration. (1999). Meeting the challenge: HRSA and managed care. Rockville, MD: Author.

22. Hummel, J., \& Pirzada, S. (1994). Estimating the cost of using non-physician providers in an HMO: where would the savings begin? HMO Practice, 8 (4), 162-164. 
23. Intrator, O, Zinn, J., \& Mor, V. (2004). Nursing home characteristics and potentially preventable hospitalization of long-stay residents. Journal of the American Geriatrics Society, 52, 1730-1736.

24. Kaiser Family Foundation. US health care costs. Available at: http://www.kaiseredu.org/topics_im.aspimID=1\&parentID=61\&id=358. Updated July 2009.

25. Kernick D and Scott A (2002). Economic approaches to doctor/nurse skill-mix: problems, pitfalls, and partial solutions, British Journal of General Practice, 53 42-46.

26. Kitzman H and Groth S (2003). Long-term outcomes of advanced nursing practice, in Mezey M, McGivern D, Sullivan-Marx E and Greenberg S (Eds) Nurse Practitioners Evolution of Advanced Practice (4th ed) Springer Publishing Company, New York.

27. Koska, M. (1989). Alternative care: Indigent care and overcrowding threaten EDs. Hospitals, 6-70.

28. Kowalczyk L. ER visits, costs in Mass. climb. Boston Globe. April 24, 2009. Available at: http://www.boston.com/news/local/massachusetts/articles/2009/04/24/er_visits_costs_in_mass_climb.

29. Law Y and Lam K (1999). A randomized controlled trial comparing midwife-managed care and obstetrician-managed care for women assessed to be at low risk in the initial intrapartum period, Journal of Obstetric and Gynecology Research, 25 (2) 107-112.

30. McCallum, B. T., \& Jacoby, P. F. (2009, January). Medical outsourcing: Reducing client's health care risks. Benefits and Compensation Digest, 46 (1) 26-32.

31. McGrath, S. (1990). The Cost-Effectiveness of Nurse Practitioners, Nurse Practitioner, 15(7) 40-42.

32. Mundinger, M. O., et al. (2000) Primary Care Outcomes in Patients Treated by Nurse Practitioners or Physicians: a Randomized Trial. Journal of the American Medical Association, 283 (1), 59-68.

33. Murphy A. L., Martin-Mise L., Misener R., Cooke C. \& Sketris, I. (2009) Administrative claims data analysis of nurse practitioner prescribing for older adults. Journal of Advanced Nursing 65(10), 2077-2087 doi: $10.1111 / \mathrm{j} .1365-2648.2009 .05069 . x$

34. Nichols L (1992). Estimating Costs of Under-using Advanced Practice Nurses, Nursing Economics, 10 (5) 343-351.

35. Office of Technology Assessment (1981). The Cost and Effectiveness of Nurse Practitioners. Washington, DC: US Government Printing Office.

36. Office of Technology Assessment (1986). Nurse Practitioners, Physician Assistants, and Certified Nurse Midwives: A Policy Analysis. Washington, DC: US Government Printing Office.

37. Paez, K. A., Allen, J. K. (2006). Cost-effectiveness of nurse practitioner management of hypercholesterolemia. Journal of the American Academy of Nurse Practitioners, doi:10.1111/j.17457599.2006.00159.x

38. Pear, R. (2004, January 4). Health spending rises to record 15\% of economy. The New York Times, A16.

39. Pinkerton, J., \& Bush, H. (2000). Nurse practitioners and physicians: Patients' perceived health and satisfaction with care. Journal of the American Academy of Nurse Practitioners, 121(6), 211-217.

40. Sears, J., Wickizer, T., Franklin, G., Cheadie, A., \& Berkowitz, B. (2007). Expanding the role of nurse practitioners: Effects on access to care for injured workers. Journal of Rural Health, 24 (2), 171-178.

41. Smith, C., Cowan, C., Heffler, S., \& Catlin, A. (2006). National health spending in 2004: Recent slowdown led by prescription drug spending. Health Affairs, 25(1), 186-196.

42. Steinbrook R. (2008). Health care reform in Massachusetts: expanding coverage, escalating costs. New England Journal of Medicine, 358(26), 2757-2760.

43. Venning P, Durie A, Roland M, Roberts C and Leese B (2000). Randomized controlled trial comparing cost-effectiveness of general practitioners and nurse practitioners in primary care, British Medical Journal, 320 (7241) 1048-1053.

44. West D.A., West T. D., Malone P. J. (1998). Managing capital and administrative (indirect) costs to achieve strategic objectives: the dialysis clinic versus the outpatient clinic (1998). Journal of Health Care Finance, 25 (2):20-34.

45. Vincent, D. (2002). Using cost-analysis techniques to measure the value of nurse practitioner care. International Nursing Review, 49, 243-249. 